\title{
Notas Sobre o Estudo das Políticas Públicas e a Intervenção Jurisdicional para a Garantia dos Direitos Fundamentais
}

\section{Bruno Makowiecky Salles}

Juiz de Direito no Estado de Santa Catarina. Mestrando em Direito pela Universidade do Vale do Itajaí (Univali). Especialista em Direito Material e Processual Civil pelo Complexo de Ensino Superior de Santa Catarina (Cesusc). Especialista em Direito e Gestão Judiciária pela Academia Judicial do Poder Judiciário do Estado de Santa Catarina. Bacharel em Direito pela Universidade Federal de Santa Catarina (UFSC). brunomakosalles@terra.com.br

\section{Resumo}

0 estudo da criação e da instituição das políticas públicas, por parte dos poderes Legislativo e Executivo, revela uma necessária conexão com a concretização dos direitos fundamentais. A partir desta lógica, e com a utilização do método dedutivo, investiga-se a legitimidade da intervenção jurisdicional em matéria de políticas públicas para a garantia de referidos direitos, nas hipóteses de distanciamento entre eles e as políticas estatais.

Palavras-chave: Políticas públicas. Direitos fundamentais. Poder judiciário. 


\title{
NOTES ABOUT THE STUDY OF PUBLIC POLICY AND JUDICIAL INTERVENTION TO WARRANTIES OF FUNDAMENTAL RIGHTS
}

\begin{abstract}
The study of the creation and implementation of public policies, on the part of the Legislative and Executive, reveals a necessary connection with the realization of Fundamental Rights. From this logic, using the deductive method, this article investigate the legitimacy of judicial intervention in matters of public policy to guarantee such rights, in case of distance between them and public policies.
\end{abstract}

Keywords: Public policy. Fundamental rights. Judiciary.

\section{Sumário}

1. Introdução. 2. Os Direitos Fundamentais. 3. A Teoria da Tripartição das Funções do Estado. 4. As Políticas Públicas. 5. A Fixação das Políticas Públicas. 6. A Implantação das Políticas Públicas. 7. A Vinculação entre Políticas Públicas e Direitos Fundamentais. 8. A Dimensão Política da Jurisdição. 9. Considerações Finais. 


\section{INTRODUÇÃO}

O presente artigo tem como objeto investigar a conexão existente entre os direitos fundamentais e o estabelecimento das políticas públicas, incluídos os processos de fixação legislativa e instituição executiva de referidas políticas. A partir de tal investigação o estudo propõe-se a abordar, dentro do contexto de tripartição das funções do Estado, a possibilidade de controle judicial das políticas públicas nos casos em que estiverem dissociadas dos direitos fundamentais.

Para fins de desenvolvimento, a exposição foi sistematizada de forma que, em um primeiro momento, promoveu-se uma sucinta definição da categoria direitos fundamentais, destacando-se as principais funções das normas que definem tais direitos. A seguir realizou-se uma exposição sinóptica sobre o princípio da tripartição dos poderes e sua finalidade no âmbito do Estado Constitucional. Prosseguindo, formulou-se a conceituação da expressão políticas públicas e a explicitação dos processos de fixação e execução de tais políticas, ressaltando-se os limites à discricionariedade vigente nessas atividades e a vinculação entre as políticas e os direitos fundamentais. Por fim, partindo das noções trabalhadas nos tópicos anteriores, analisou-se a possibilidade de intervenção judicial destinada a impor aos demais poderes, em matéria de políticas públicas, a primazia dos direitos fundamentais, explorando-se a dimensão política da jurisdição constitucional.

O método de abordagem utilizado no estudo é o dedutivo-indutivo.

Quanto à metodologia, fez-se uso da descrição e da prescrição, desenvolvendo-se a pesquisa por meio de documentação indireta, abrangendo análises documental e bibliográfica. 


\section{OS DIREITOS FUNDAMENTAIS}

Os direitos fundamentais, na atual concepção, podem ser definidos como aqueles direitos inerentes à pessoa humana, singular e coletivamente considerada, que, extraídos do plano dos direitos humanos (perspectiva jusnauralista), são internalizados nas disposições constitucionais de determinado ordenamento (perspectiva juspositivista espaço-temporal), adquirindo normatividade preordenada à promoção dos ideais da liberdade, da igualdade e da solidariedade nas relações entre o Estado e os cidadãos e os cidadãos entre si.

Segundo José Joaquim Gomes Canotilho (2003, p. 377):

Os direitos fundamentais serão estudados enquanto direitos jurídicopositivamente vigentes numa ordem constitucional. Como iremos ver, o local exacto dessa positivação é a constituição. A positivação de direitos fundamentais significa a incorporação na ordem jurídica positiva de direitos considerados "naturais e inalienáveis" do indivíduo. (...) Sem esta positivação jurídica, os direitos do homem são esperanças, aspirações, idéias, impulsos, ou, até, por vezes, mera retórica política, mas não direitos protegidos sob a forma de normas (regras e princípios) de direito constitucional.

Daí segue que, uma vez introjetados, sob a forma de normas-regras e de normas-princípios (Alexy, 2008), no âmbito dos Estados Constitucionais, passando a ostentar os atributos da imperatividade e da exigibilidade típicos das normas positivadas (Ferreira de Melo, 2000), os direitos fundamentais, por representarem valores básicos da humanidade (carga axiológica), assumem papel de singular relevo no cenário jurídico. Despontam, assim: (1) como fator de limitação do poder estatal, de participação democrática e de proteção dos cidadãos, assegurando uma esfera de individualidade e a promoção de um mínimo existencial; (2) como critério de aferição da legitimidade constitucional dos atos e omissões estatais, ainda que das condutas de natureza política; (3) como parâmetro para formula- 
ção de juízos de validade sobre os atos e as omissões do poder público; e, ainda, (4) como uma diretriz conformadora da atuação do poder público nos sistemas Executivo, Legislativo e Judiciário ${ }^{1}$.

Consoante Ingo Wolfagang Sarlet (2009, p. 59):

Os direitos fundamentais constituem, para além de sua função limitativa de poder (que, ademais, não é comum a todos os direitos), critérios de legitimação do poder estatal e, em decorrência, da própria ordem constitucional, na medida em que o poder se justifica por e pela realização dos direitos do homem e que a idéia de justiça é hoje indissociável de tais direitos. É precisamente nesse contexto que assume relevo a lição de Ferrajoli, no sentido de que todos os direitos fundamentais equivalem a vínculos substanciais que condicionam a validade substancial das normas produzidas no âmbito estatal, ao mesmo tempo em que expressam os fins últimos que norteiam o moderno Estado Constitucional de Direito.

Dada a magnitude do papel exercido pelos direitos fundamentais nos Estados Constitucionais, consolidada por concepções filosóficas, históricas e, agora, jurídicas (Cruz, 2004), referidos direitos atualmente integram, junto com os princípios estruturais e organizacionais do Estado, o aspecto nuclear das disposições previstas em uma Constituição, representando, como linha geral, regras ou princípios de estatura materialmente constitucional ${ }^{2}$ e de observância obrigatória.

${ }^{1}$ Dada a supremacia da Constituição e a circunstância de figurar como fundamento de validade da produção legislativa (tanto prévia quanto ulterior), é possível afirmar que as normas constitucionais têm potencial para provocar uma ruptura com a ordem jurídica anterior com ela incompatível (natureza ab-rogatória), admitindo a remanência em vigor apenas das leis materialmente compatíveis (natureza receptiva), bem como para vincular as atividades de criação legiferante e administrativa (natureza normogenética), e, em todo caso, para nortear a interpretação e a aplicação do Direito (natureza bussolar).

${ }^{2}$ As normas materialmente constitucionais, entendidas como as que integram, efetivamente, o conteúdo de uma Constituição, são aquelas pertinentes à organização do poder, à distribuição de competências, ao exercício da autoridade, à forma de governo e aos direitos fundamentais individuais e sociais. As demais normas constantes da Constituição que 


\section{A TEORIA DA TRIPARTIÇÃO DAS FUNÇÕES DO ESTADO}

A teoria da repartição dos poderes do Estado, ${ }^{3}$ cuja gênese, na versão mais aproximada, remonta a Montesquieu (1995), foi concebida como método de contenção do arbítrio estatal e de promoção dos direitos fundamentais. Centrada na ideia de que quem concentra o poder tende a abusar, a teoria da separação propôs a fragmentação dos organismos que exercem a força estatal, atribuindo (1) ao poder Legislativo a edição de normas aptas a inovar na ordem jurídica, com a criação, a extinção e a modificação de direitos; (2) ao poder Executivo a atuação concreta destinada à efetivação dos mandamentos legais e (3) ao poder Judiciário a resolução dos conflitos de interesses para o restabelecimento da ordem jurídica violada. Cada um desses poderes, ao lado das referidas funções típicas, desempenha, segundo a teoria, também algumas funções atípicas aptas a garantir-lhes autonomia e independência, bem como a fiscalizar o exercício dos demais poderes, instituindo-se um sistema de freios e contrapesos pelo qual um poder freia o outro, obstaculizando o abuso estatal e garantindo os direitos fundamentais.

versem sobre assuntos diversos são apenas formalmente constitucionais, pelo fato único de se situarem em seu corpo normativo, mas não versam sobre matéria de cunho essencialmente constitucional (Bonavides, Paulo. Curso de direito constitucional. 6. ed. São Paulo: Malheiros, 1996. p. 63).

${ }^{3}$ O vocábulo "poder", a rigor, não é exato. O poder estatal é uno e indivisível. O que ocorre é a repartição das funções Executiva, Legislativa e Judiciária entre diferentes órgãos do Estado, de maneira que, em princípio, a função Executiva seja outorgada ao poder Executivo e assim por diante. Tal correlação, porém, não é universalmente válida, pois, tendo em vista a existência de funções atípicas, não raro ocorre de um poder exercer função inerente, em regra, a outro, tal como ocorre quando o poder Judiciário se autoadministra (função executiva) ou quando o poder Legislativo instaura Comissões Parlamentares de Inquérito (função judiciária) ou, ainda, quando o Executivo edita medidas provisórias (função legislativa), dentre outros exemplos. 
Sobre o assunto, Joel de Menezes Niebuhr (2001, p. 30-31) observa:

O cumprimento dos direitos fundamentais pressupõe que os poderes políticos sejam todos limitados, devendo haver mecanismos concretos de controle. Em outras palavras, o respeito aos direitos fundamentais e a legitimidade de todo o processo jurídico-político dependem da existência de limites ao exercício dos poderes, o que se faz através da distribuição de funções a órgãos distintos, para que cada um controle o outro, percebendo-se, às escâncaras, o núcleo da teoria da divisão de poderes [...] Importa reforçar o argumento de que divisão dos poderes e direitos fundamentais são instituições interligadas. Para que os direitos fundamentais recebam eficácia, é preciso que o exercício do poder seja limitado e controlado, o que só pode ser feito com a repartição das esferas de poder, em que um controla o outro.

Integrando a tradição constitucional brasileira, a separação dos poderes foi consagrada na atual Constituição como princípio fundamental da República (artigo $2^{\underline{0}}$ da CF), possuindo status destacado na organização do Estado brasileiro.

\section{AS POLÍTICAS PÚBLICAS}

A expressão políticas públicas designa um conjunto de ações, ou mesmo uma conduta isolada do poder público, com a finalidade de efetivar os direitos fundamentais e cumprir os postulados do Estado Democrático de Direito (Freire Júnior, 2005). Trata-se do resultado de uma atividade governamental realizada por autoridades com legitimidade constitucional, que contempla, essencialmente, uma opção pelos fins a serem perseguidos (prioridades), um programa de ação para instituí-los e os métodos (incluídos, aqui, os financeiros) a serem empregados nessa instituição. 
De acordo com José dos Santos Carvalho Filho (2008, p. 111):

Políticas públicas, por conseguinte, são as diretrizes, estratégias, prioridades e ações que constituem as metas perseguidas pelos órgãos públicos, em resposta às demandas políticas, sociais e econômicas, para atender aos anseios oriundos das coletividades. Vale explicar o conceito.

Diretrizes são os pontos básicos dos quais se originara a atuação dos órgãos; estratégias correspondem ao modus faciendi, isto é, aos meios mais convenientes e adequados para a consecução das metas; prioridades são as metas obtidas mediante processo de opção ou escolha, cuja execução antecederá à exigida para outros objetivos; e ações constituem a efetiva atuação dos órgãos para alcançar seus fins.

As metas constituem os objetivos a serem alcançados: decorrem, na verdade, das propostas que nortearam a fixação das diretrizes. Por fim, temos os elementos mobilizadores, ou seja, as causas responsáveis pelas políticas públicas. De um lado, as demandas sociais, políticas e econômicas, representando os fatos que, em determinado lugar e tempo, rendem ensejo à perseguição de metas específicas. De outro, os anseios das coletividades, que é o que resulta das vontades coletivas, vale dizer, os resultados que, efetivamente, podem causar satisfação às pessoas em geral.

A concretização das políticas públicas, com a fixação e a efetivação das ações estatais destinadas à realização do bem comum, está relacionada com o perfil de cada Estado. A Constituição do país estabelece os campos e programas de ação a serem priorizados pela atuação do poder público (saúde, educação, segurança, livre-iniciativa, proteção ambiental, etc.), vinculando-o à satisfação dessas prioridades (Pontes Filho, 2008), sem prejuízo da atuação em setores não destacados de forma expressa, na Constituição, mas reputados relevantes pelos representantes eleitos pelos cidadãos no vasto campo abrangido pelo raio de intervenção estatal. 


\section{A FIXAÇÃO DAS POLÍTICAS PÚBLICAS}

Fixar políticas públicas significa, em síntese, defini-las ou criá-las. O processo de fixação das políticas públicas constitui atividade legislativa que se materializa, essencialmente, em dois níveis subsecutivos. Em um primeiro nível, a Constituição da República, ao expressar os objetivos gerais da nação, os direitos fundamentais dos cidadãos e os campos de ação do Estado, define os direitos desde logo fruíveis e as principais ações e metas a serem alcançadas pelos programas estatais, vinculando-o à satisfação dessas prioridades. Em um segundo nível, complementar às disposições constitucionais, a legislação infraconstitucional, tendo como veículos normativos, sobretudo, leis em acepção formal, enuncia os mecanismos de instituição das políticas já consagradas ou institui, ela própria, as novas diretrizes e os respectivos métodos de aplicação.

O fenômeno de fixação das políticas públicas é sujeito a fatores reais de poder. O interesse público (cambiante) é obtido a partir da pauta de prioridades dos governos e parlamentos eleitos após o resultado democrático das urnas, variando em razão da pressão política de grupos sociais e econômicos, da ideologia dominante entre os representantes eleitos e dos próprios meios de comunicação (Appio, 2008). A relação de prioridades auferida dessas tensões, por sua vez, é complementada por estudos/dados técnicos sobre os sistemas sociais, econômicos e estatísticos, bem como por relatórios sobre as necessidades sociais, os déficits de determinados programas estatais e os recursos (financeiros, humanos e estruturais) disponíveis para o atendimento das demandas, extraindo-se de tais dados os aportes utilizados no prognóstico dos focos (programas) de atuação do Estado (Oliveira; Horvath, 2003). Esses prognósticos, enfim, se traduzem em produtos legislativos que fixam ou especificam as políticas públicas a serem providas, observada a necessária conformidade com a escala dos valores constitucionais. 
Formular políticas públicas integra, portanto, a chamada competência legislativa (lato sensu) prevista na Constituição e insere-se na categoria dos chamados atos de governo, porque se relaciona à superior gestão da vida estatal (Bandeira de Mello, 2003), realizando-se basicamente mediante a edição de leis pelo poder Legislativo e a iniciativa de encaminhamento de leis (notadamente as orçamentárias) pelo Executivo. Trata-se de tarefa envolta em elevado grau de discricionariedade, competindo, em princípio, aos órgãos responsáveis pela produção legislativa, baseados em estudos prévios, eleger com liberdade, entre as variantes que compõem o conceito jurídico indeterminado de interesse público, quais são as prioridades que devem ser encampadas pelo Estado, desde que compatíveis com os postulados e as diretrizes constitucionais, bem como quais os meios de ação (planejamento), os recursos disponíveis e o conteúdo técnico das prestações do poder público necessárias à concretização dessas prioridades.

\section{A INSTITUIÇÃO DAS POLÍTICAS PÚBLICAS}

A instituição das políticas públicas na realidade fenomênica constitui o passo subsequente ao processo de definição das linhas de atuação do poder estatal. Assim, uma vez definidas, na Constituição, na legislação infraconstitucional e nas leis orçamentárias (esfera legiferante), as pautas de atuação do Estado, a concretização das políticas públicas encampadas pelo Parlamento, com a participação prévia (iniciativa) ou posterior (sanção ou veto) do poder Executivo (atividade política colegislativa e/ ou de direção), compõem a chamada competência administrativa (lato sensu) prevista na Constituição e repartida entre os entes federados, representando função administrativa típica de concreção de comportamentos infralegais ${ }^{4}$ destinados a executar as diretrizes governamentais nas áreas do serviço, da intervenção, do fomento e da polícia.

\footnotetext{
${ }^{4}$ Nos comportamentos infralegais de concreção das políticas públicas inserem-se tanto a execução de atos materiais como a atividade normativa do poder Executivo na edição dos atos necessários ao pleno cumprimento das leis. Essa atividade normativa da administração pública, sempre ads-
} 
Eduardo Appio (2008, p. 135), acerca do tema, anota:

As questões políticas dizem respeito à prerrogativa de escolha dos meios através dos quais o governante eleito irá executar seu programa. A atividade administrativa é o instrumento de execução das políticas públicas, sociais e econômicas, sendo que as primeiras consistem em intervenções estatais que a Administração Pública realiza com o objetivo de assegurar a universalidade do acesso aos serviços sociais básicos, como saúde, segurança pública e educação.

A missão de concretizar as políticas públicas, competindo institucionalmente, em regra, ao poder Executivo, desenvolve-se conforme as previsões das leis orçamentárias que regulamentam os dispêndios públicos. Os gastos públicos formalizam-se paulatinamente, no decorrer do exercício financeiro, de acordo com as disponibilidades de caixa e as prioridades do administrador. A atividade de execução orçamentária é informada por dose de discricionariedade, embora essa discricionariedade assuma proporções (significativamente) inferiores à existente no momento da fixação das políticas públicas. Cresce atualmente, aliás, a ideia de que o orçamento público sofre um processo histórico de reformulação, deixando de figurar como mera peça contábil (estática) de previsão de receitas e autorização de despesas para se transformar em um efetivo instrumento (dinâmico) de atuação do Estado nas relações sociais e econômicas.

As disposições orçamentárias, nesse cenário, passam de mera proposta (uma peça de ficção) a plano de ação vinculativo da conduta do Estado (uma peça real), ressalvadas as situações justificadas como riscos fiscais ou contrariedades fáticas e jurídicas, sob pena de inexecução ilegal

trita aos limites da mera regulamentação, sem aptidão para inovar na ordem jurídica (princípio da legalidade), justifica-se em razão do grau de abstração de determinadas leis que instituem políticas públicas, com densidades normativas atenuadas, e em virtude, também, da complexidade técnica das medidas necessárias à efetivação dessas políticas, atraindo a necessidade de estudos complementares. 
do orçamento. E daí resulta que o poder Executivo não possui um cheque em branco na execução de políticas públicas, estando vinculado, por exemplo, à aplicação de um percentual mínimo de receita constitucionalmente afetado para as áreas de educação, da saúde e a fundos (artigo 167, IV, c/c artigos 198, $\S 2^{\circ}$, e 212 da CF), bem como ao cumprimento das leis orçamentárias, à vedação de despesas não previstas e a outros fatores.

\section{A VINCULAÇÃO ENTRE POLÍTICAS PÚBLICAS E DIREITOS FUNDAMENTAIS}

A Constituição da República, ao ordenar o funcionamento dos poderes do Estado, gera, como consequência, a submissão de tais poderes aos mandamentos constitucionais (princípio da supremacia). Significa que as disposições constitucionais não podem ser violadas pela conduta comissiva ou omissiva dos poderes constituídos. Como os direitos fundamentais integram um dos aspectos nucleares das disposições constitucionais, representando normas materialmente constitucionais, tem-se que as ações dos poderes do Estado devem manter-se harmônicas aos direitos fundamentais de todas as dimensões, promovendo-os na máxima extensão possível, sendo defeso negaceá-los ou preteri-los, na concretização das políticas públicas, para fins de atendimento a metas casuísticas, eleitoreiras e/ou ao mesmo interesse secundário do Estado. ${ }^{5}$

Segundo Alexandre Morais da Rosa (2002, p. 44):

\footnotetext{
${ }^{5}$ Há conhecida distinção entre os interesses públicos primário e secundário. O interesse público primário refere-se ao interesse do Estado na realização do bem comum, apreendido a partir dos interesses do todo, do conjunto social, dos indivíduos enquanto partícipes da sociedade. O interesse público secundário, noutro giro, contrapõe-se a essa noção por traduzir os interesses individuais e financeiros do Estado-administração como pessoa jurídica de Direito público, ou os interesses (de variada natureza) do governo que se distanciem de critérios de utilidade social.
} 
No Estado Democrático de Direito, todos, absolutamente todos os atores jurídicos devem ter para com a Constituição Federal estreita ligação, concretizando-a na sua maior extensão possível, primordialmente no tocante aos Direitos Fundamentais. Existe a necessidade orgânica de convergência das práticas jurídicas e sociais aos regramentos constitucionais relativos aos Direitos Fundamentais, estabelecendo-se, portanto, um sistema de garantias simultâneo de preservação e realização.

Daí resulta que as normas sobre direitos fundamentais devem conformar o comportamento (legislativo e executivo) dos poderes constituídos, reduzindo a margem de liberdade nas tarefas de definir o interesse público, de fixar as metas e programas prioritários(as) e de instituir as políticas públicas tidas como primaciais. Afirma-se, aliás, que "não existe uma independência absoluta em favor da Administração Pública para definir qual seja o interesse público prevalente” (Appio, 2008, p. 123), na medida em que as opções dos poderes do Estado só se afiguram legítimas se e quando afinadas à escala axiológica plasmada nas normas constitucionais sobre direitos fundamentais, vedado se revelando aos órgãos estatais delas distanciar-se, sob pena de incursão em inconstitucionalidade(s) por ação ou por omissão.

Para Valmir Pontes Filho (2008, p. 374):

É razoável concluir que quaisquer que sejam os programas e projetos governamentais, ou eles se adaptam aos princípios constitucionais, ou, inexoravelmente, haverão de ser tidos como inválidos, juridicamente insubsistentes e, portanto, sujeitos ao mesmo controle jurisdicional de constitucionalidade a que se submetem as leis. Como igualmente ponderado é observar que a abstinência do governo em tornar concretos, reais, os fins e objetivos inseridos em tais princípios e diretrizes constituirá, inelutavelmente, uma forma clara de ofensa à Constituição e, consequientemente, de violação de direitos subjetivos dos cidadãos. 
A vinculação da atuação política, jurídica e social do Estado à promoção dos direitos fundamentais se projeta, portanto, nas esferas da fixação (legislativa) e da efetivação (executiva) de políticas públicas (Moreira Neto, 2008), as quais consistem "nos meios necessários para a efetivação dos direitos fundamentais, uma vez que pouco vale o mero reconhecimento formal de direitos se ele não vem acompanhado de instrumentos para efetivá-los” (Freire Júnior, 2005, p. 48). Essa vinculação expande-se ao aspecto financeiro-orçamentário ligado ao tema, sendo lícito exigir que as autorizações para gastos previstas nas leis orçamentárias, além de observarem as vinculações obrigatórias (artigo 167, IV, c/c artigos 198, §2º e 212 da $\mathrm{CF}$ ), sejam concebidas com o objetivo de fomentar a ampliação dos direitos fundamentais. Também é lícito exigir que a execução orçamentária canalize a aplicação de recursos na promoção de tais direitos (saúde, educação, meio ambiente, segurança pública, etc.) em detrimento de outras metas de menor envergadura constitucional, de criação apenas infraconstitucional ou de interesse exclusivo do governo (propaganda institucional, obras, eventos, etc.). Na execução do orçamento, aliás, é cabível a advertência de que "não pode haver um retrocesso social, tampouco as alterações no manejo orçamentário das receitas e despesas (mais ou menos vinculadas) podem impactar desproporcionalmente os meios financeiros que visam garantir progressivamente os direitos fundamentais” (Pinto, 2008, p. 75).

Consoante Ricardo Lobo Torres (2010, p. 387):

A vida financeira e orçamentária do país deve se ajustar ao culto da justiça e dos direitos humanos. Com efeito, duas idéias básicas, de conteúdo ético e jurídico, passam a orientar a humanidade na virada do século e do milênio: a da supremacia dos direitos humanos e a da busca da justiça. $O$ constitucionalismo hodierno não tem por missão apenas garantir uma ordem financeira equilibrada, senão que se orienta no sentido de obtê-la e sustentá-la com vista à defesa dos direitos humanos e à procura da justiça material. 
Dessa exposição resulta que o desvio de rota pelos poderes Legislativo e Executivo, com o evidenciado descaso ou o distanciamento injustificado, seja na órbita política, seja no âmbito administrativo, em relação às normas constitucionais que definem os direitos fundamentais da população, constitui matéria sindicável pelo poder Judiciário em caso de lesão ou ameaça de lesão a direito (Moreira Neto, 2008), diante, inclusive, da cláusula da inafastabilidade da jurisdição (artigo 5º, XXXV, da CF).

\section{A DIMENSÃO POLÍTICA DA JURISDIÇÃO}

O controle de políticas públicas, especialmente no plano dos direitos fundamentais, não representa província alheia à atuação jurisdicional. Ainda que o desenvolvimento de políticas preestabelecidas na Constituição represente atribuição primária dos poderes Legislativo e Executivo, o descumprimento das normas constitucionais sobre direitos fundamentais

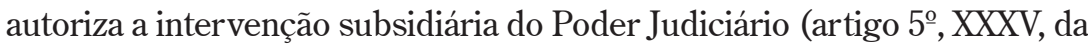
$\mathrm{CF})$, no exercício da jurisdição constitucional, ${ }^{6}$ notabilizada por ter uma dimensão política.

O déficit histórico na instituição dos direitos fundamentais, em especial dos direitos sociais prestacionais, associado a fatores como a amplitude da Constituição e a constitucionalização do Direito, originou o fenômeno da judicialização das relações políticas e sociais (ou da politização do universo jurídico), conferindo ao poder Judiciário um papel de protagonismo na "paisagem institucional brasileira” (Barroso, 2009). Essa

\footnotetext{
${ }^{6}$ A delimitação do objeto da chamada jurisdição constitucional constitui questão controversa. Parte da doutrina considera como abrangido por tal expressão apenas o controle concentrado de constitucionalidade, enquanto outra parte a estende, também, ao controle difuso. Há, ainda, uma terceira corrente, mais ampla, que reputa a jurisdição constitucional como compreensiva não só das atividades de controle (concentrado e difuso) de constitucionalidade, mas também da proteção dos direitos fundamentais (Dantas, 2010, p. 45). É nesse último sentido que a expressão foi empregada anteriormente.
} 
judicialização da política, é importante destacar, não implica a apropriação da atividade política primária pelas autoridades judiciárias, expressando, unicamente, que determinadas matérias polêmicas inserem-se no raio de alcance das normas constitucionais e podem ser traduzidas, em determinadas circunstâncias, em postulações jurídicas e/ou fundamentos de direitos subjetivos, transferindo ao poder Judiciário a apreciação de tal temática.

Nesse sentido são as observações de Lenio Luiz Streck (2009, p. 52):

Por tudo isso, é possível sustentar que, no Estado Democrático de Direito, ocorre um sensível deslocamento do centro de decisões do Legislativo e do Executivo para o plano da justiça constitucional. Pode-se dizer, nesse sentido, que no Estado Liberal, o centro de decisão apontava para o Legislativo (o que não é proibido é permitido, direitos negativos); no Estado Social, a primazia ficava com o Executivo, em face da necessidade de realizar políticas públicas e sustentar a intervenção do Estado na economia; já no Estado Democrático de Direito, o foco de tensão se volta para o Judiciário. Dito de outro modo, se com o advento do Estado Social o foco de poder/tensão passou para o Poder Executivo, no Estado Democrático de Direito há uma modificação desse perfil. Inércias do Executivo e falta de atuação do Legislativo passam a poder ser supridas pelo Judiciário, justamente mediante a utilização de mecanismos jurídicos previstos na Constituição que estabeleceu o Estado Democrático de Direito. Isso, à evidência, exigirá um controle das decisões judiciais e dos julgadores. Afinal, se é inexorável que alguém tenha que decidir e se é inexorável o crescimento das demandas por direitos (fundamentais-sociais, principalmente) e com isso aumente o espaço de poder da justiça constitucional, parece evidente que isso não pode vir a comprometer um dos pilares sustentadores do paradigma neoconstitucionalista: a democracia [...] Tem-se que ter em mente, entretanto, a relevante circunstância de que, se no processo constituinte optou-se por um Estado intervencionista, visando a uma sociedade mais justa, com a erradicação da pobreza, etc., deverse-ia esperar que o Poder Executivo e o Legislativo cumprissem tais programas especificados na Constituição. Acontece que a Constituição 
não está sendo cumprida. As normas-programa da Lei Maior não estão sendo implementadas. Por isso, na falta de políticas públicas cumpridoras dos ditames do Estado Democrático de Direito, surge o Judiciário como instrumento de resgate dos direitos não realizados. Por isso a inexorabilidade desse sensível deslocamento antes especificado. Com todos os cuidados que isso implica.

Convém destacar, no ponto, que a teoria da tripartição das funções do Estado, em sua leitura atual, não deve constituir um óbice incontornável à atuação jurisdicional. Como não se trata de uma teoria atemporal ou de um fim em si mesmo, mas, como visto, de uma técnica de sofreamento do abuso para a promoção dos direitos fundamentais, a tripartição dos poderes varia sua funcionalidade conforme variam as necessidades do corpo social e os direitos fundamentais previstos nas Constituições. Em tal quadro, as inter-relações entre os poderes, nos dias de hoje, não devem ser provisionadas, estritamente, a partir das funções (estáticas) que compete a cada poder desempenhar, de maneira a se considerar invasiva toda e qualquer interferência de um poder em função que, em princípio, seria típica de outro. A simbiose entre os poderes deve ter como eixo de referência as normas constitucionais (incluídas as de direitos fundamentais), de modo a admitir-se que, caso um poder não cumpra injustificadamente as normas que lhe impõe determinada conduta ou abstenção, ocorra a intervenção cooperativa de outro poder para assegurar a primazia dos direitos dos cidadãos e da ordem constitucional, cumprindo-se, com tal ciclo, a finalidade a que se propõe a teoria.

Conforme José Luis Bolzan de Morais e Walber de Moura Agra (2004, p. 1.064):

$\mathrm{O}$ enquadramento das funções estatais dentro do esquema da rígida tripartição dos poderes não mais corresponde às necessidades de uma sociedade pós-moderna. Para atender às cambiantes demandas da coletividade há necessidade de uma reestruturação da concepção 
de separação dos poderes, delineando-a de um modo mais eficaz para preservar os direitos fundamentais, assegurando a substanciação dos mandamentos contidos na Constituição.

A reestruturação do princípio da separação dos poderes agrava-se com a adoção de um Estado Democrático de Direito efetivo, em que os Poderes Executivo e Legislativo devem cumprir o conteúdo da Carta Magna. [...] A nova perspectiva do princípio da separação dos poderes é não mais conceber a atuação dos poderes de forma estanque e individualizada, mas em um sentido mais flexível, de cooperação para a realização dos direitos fundamentais, predominando uma unidade para a obtenção deste objetivo.

A leitura proposta sobre a separação das funções do Estado, atraindo como nota a recíproca interferência para o cumprimento das disposições constitucionais, reflete-se, também, no conceito tradicional de legitimidade para a condução dos atos estatais. Tal conceito passa a se desprender dos postulados de um sistema fundado exclusivamente na representação popular para fundar-se em um critério objetivo correspondente à conformação das práticas do Estado às normas constitucionais (Villalón, 1999). O sistema de representação popular, aliás, não é garantia de legitimidade das ações públicas. A presunção de legitimidade que deriva apenas do procedimento democrático e da forma de investidura nem sempre é suficiente, podendo ser afastada perante a "evidência de ilegitimidade no desempenho e na destinação do poder (argumento legitimatório)", dado que “a manifestação da vontade estatal, ainda que democraticamente recolhida, se subordina à axiologia constitucional (argumento de constitucionalidade) e, ainda, a mera representação política do cidadão, nos executivos e nos legislativos, não mais comunica sua vontade” (Moreira Neto, 2008, p. 54). O sistema representativo, portanto, não serve como parâmetro único para aferição da legitimidade das decisões políticas, mostrando-se possível ao poder Judiciário, ainda que não disponha de representatividade popular 
imediata, interferir nas ações e omissões dos demais poderes sempre que se caracterizar a ilegitimidade (material) da ação ou da omissão por violação sistemática a normas-regras e aos princípios constitucionais.

A tensão existente, por vezes, entre o princípio democrático (formal) e a efetivação, pelo poder Judiciário, dos direitos fundamentais, exsurge porque tais direitos "são posições tão importantes que a decisão de garanti-los ou não garanti-los não pode ser simplesmente deixada para a maioria parlamentar simples” (Alexy, 2008, p. 446), não bastando que a Constituição se limite a explicitá-los, sem assegurá-los, para que, com base na invocação do princípio democrático (formal), possam ser negaceados "pela coincidência entre a vontade política do Estado e a vontade popular em um qualquer momento" (Miranda, 1993, p. 178). Para a própria democracia (material), cujo alcance passa pelo cumprimento dos direitos fundamentais, é necessário que o poder Judiciário afirme tais direitos perante ações ou omissões de maiorias episódicas, exercendo, por vezes, uma legítima função contramajoritária (Binenbjom, 2001) destinada a criar um quadro institucional apto ao desenvolvimento democrático.

Segundo Aury Lopes Júnior (2004, p. 73):

A legitimidade democrática do juiz deriva do caráter democrático da Constituição, e não da vontade da maioria. $\mathrm{O}$ juiz tem uma nova posição dentro do Estado Democrático de Direito e a legitimidade de sua atuação não é política, mas constitucional, e seu fundamento é unicamente a intangibilidade dos direitos fundamentais. É uma legitimidade democrática, fundada na garantia dos direitos fundamentais e baseada na democracia substancial.

Assim, ainda que seja correto afirmar que a formulação e o desenvolvimento de políticas públicas em matéria de direitos fundamentais constituam atribuição dos poderes Legislativo e Executivo (cujos representantes são eleitos pelo povo e possuem mandato para proferir decisões políticas), certo é que tais circunstâncias não impedem a interferência 
judicial quando a ação ou a omissão de qualquer um desses poderes adentrar em rota de colisão com preceitos constitucionais, ${ }^{7}$ registrando-se que o poder Judiciário não é "um mero carimbador de decisões políticas das demais funções” (Freire Júnior, 2005, p. 42) e que tal pensamento não viola, na essência, a finalidade do princípio da tripartição dos poderes e/ ou postulado da democracia.

A intervenção judicial, nesse contexto, figura como um desdobramento do semblante político da jurisdição constitucional, devendo ser exercido, porém, com cautela e de forma autocontida pelo poder Judiciário (judicial self restraint). A atuação jurisdicional em matéria de políticas públicas deve ser uma prática vocacionada, exclusivamente, a conformar as ações e omissões dos demais poderes do Estado, por meio de uma espécie de interação ou diálogo institucional, aos direitos fundamentais extraídos da Constituição. Essa postura proativa, todavia, não legitima uma República de Juízes ou o solipsismo do poder Judiciário, não autorizando que o Estado-Juiz imponha, sem correspondência constitucional, desejos unilaterais ao Estado-Legislador, ao Estado-Administrador ou à sociedade, tampouco que interfira em opções técnico-políticas legítimas e discricionárias dos demais poderes. A participação política do poder Judiciário traduz medida fundamental no Estado Democrático de Direito, mas se limita a evitar a instauração de um pseudoconstitucionalismo em

\footnotetext{
${ }^{7}$ Essa colisão pode ocorrer de várias maneiras, como quando o poder público, sem base em justificativa válida, ao eleger determinada política, (1) age em desconformidade com normas que lhe impõem uma abstenção, subtraindo campo de liberdade outorgado aos cidadãos (direitos de primeira dimensão), ou (2) se abstém de cumprir ou cumpre de modo insuficiente uma norma constitucional impositiva de prestação ao Estado, priorizando ações em causa própria e/ou sem relevância social e deixando de fornecer prestações que lhe compete (direitos de segunda dimensão), ou (3) quando por ação ou omissão, causa ou permite sejam causados danos a bens de titularidade difusa ou coletiva (direitos de terceira dimensão). Nessas e em outras hipóteses os atos políticos do poder público se sujeitam a controle jurisdicional, sobretudo no que se relaciona à constitucionalidade de tais condutas.
} 
matéria de direitos fundamentais, sem significar a usurpação pura e simples, pelo Judiciário, do círculo político de atuação dos poderes Executivo e/ou Legislativo.

\section{CONSIDERAÇÕES FINAIS}

A exposição feita autoriza a formulação de algumas sínteses conclusivas.

Assim que positivados em determinado ordenamento constitucional, os direitos fundamentais adquirem o atributo da exigibilidade característico das normas jurídicas. Esses direitos destinam-se, em suma, a promover os ideais da liberdade, da igualdade e da solidariedade nas relações estabelecidas entre o Estado e os cidadãos e os cidadãos entre si, integrando o aspecto material das disposições constitucionais. Em razão disso, figuram como critério de limitação do poder, aferição da legitimidade dos atos e omissões estatais. Ademais, autorizam a formulação de juízos de validade sobre atos e omissões do poder público, figurando, ainda, como diretriz conformadora da conduta do Estado em sede executiva, legislativa e judiciária.

Dentro de tal quadro, a concretização das políticas públicas, com a fixação no plano legislativo e a instituição na esfera executiva, pelas autoridades competentes, das ações estatais destinadas à realização do bem comum, está intimamente relacionada ao atendimento das normas constitucionais definidoras dos direitos fundamentais, revelando-se relativa, nestes termos, a discricionariedade vigente na atividade legiferante e de execução orçamentária.

O controle de políticas públicas em sede de direitos fundamentais não representa, na presente realidade, um domínio alheio à atuação jurisdicional. Mesmo que a criação e a instituição políticas integrem um encargo primário dos poderes Legislativo e Executivo, o descumprimento 
das normas constitucionais sobre direitos fundamentais autoriza a intervenção subsidiária e residual do poder Judiciário (artigo $5^{\circ}, \mathrm{XXXV}, \mathrm{da} \mathrm{CF}$ ), atribuindo uma dimensão política à jurisdição constitucional, sem que isso acarrete uma violação à teoria da tripartição das funções do Estado.

O exercício da jurisdição em sua dimensão política deve ser realizado com cautela e prudência pelo Poder Judiciário. A intervenção jurisdicional nessa esfera destina-se unicamente a conformar as ações e omissões dos demais poderes do Estado aos direitos fundamentais previstos na Constituição, não autorizando o solipsismo do poder Judiciário ou chamado o governo Judiciário.

\section{REFERÊNCIAS}

ALEXY, Robert. Teoria dos Direitos Fundamentais. São Paulo: Malheiros, 2008.

APPIO, Eduardo. Controle judicial das políticas públicas no Brasil. Curitiba: Juruá, 2006.

. Discricionariedade política do poder judiciário. Curitiba: Juruá, 2008.

BANDEIRA DE MELLO, Celso Antônio. Curso de Direito Administrativo. 16. ed. São Paulo: Malheiros, 2003.

BARROSO, Luís Roberto. O direito constitucional e a efetividade de suas normas: limites e possibilidades da Constituição brasileira. 9. ed. Rio de Janeiro: Renovar, 2009.

BINENBJOM, Gustavo. A nova jurisdição constitucional brasileira. Rio de Janeiro: Renovar, 2001.

BOLZAN DE MORAIS, José Luis; AGRA, Walber de Moura. A crise e a recuperação da jurisdição constitucional. In: LEAL, Rogério Gesta; REIS, Jorge Renato dos (Orgs.). Direitos sociais e políticas públicas: desafios contemporâneos. Santa Cruz do Sul: Edunisc, 2004. V. 4. 
BONAVIDES, Paulo. Curso de direito constitucional. 6. ed. São Paulo: Malheiros, 1996.

CANOTILHO, J. J. Gomes. Direito constitucional e teoria da constituição. 7. ed. Coimbra: Almedina, 2003.

CARVALHO FILHO, José dos Santos. Políticas públicas e pretensões judiciais determinativas. In: FORTINI, Cristiana; ESTEVES, Júlio César dos Santos; DIAS, Maria Tereza Fonseca (Orgs.). Políticas públicas: possibilidades e limites. Belo Horizonte: Fórum, 2008. 377 p.

CRUZ, Paulo Márcio. Fundamentos do direito constitucional. 2. ed. Curitiba: Juruá, 2004.

DANTAS, Paulo Roberto de Figueiredo. Direito Processual Constitucional. 2. ed. São Paulo: Atlas, 2010.

FERREIRA DE MELO, Osvaldo. Dicionário de política jurídica. Florianópolis: $\mathrm{OAB} / \mathrm{SC}, 2000$.

FREIRE JÚNIOR, Américo Bedê. O controle judicial das políticas públicas. São Paulo: Revista dos Tribunais, 2005.

LOPES JÚNIOR, Aury. Introdução crítica ao processo penal. Rio de Janeiro: Lumen Juris, 2004.

MIRANDA, Jorge. Manual de Direito Constitucional. v. 4. Coimbra: Coimbra Ed., 1993. V. 4.

MONTESQUIEU, Charles Louis de Secondat. O espirito das leis. Trad. Fernando Henrique Cardoso e Leôncio Martins Rodrigues. Brasília: UnB, 1995. MOREIRA NETO, Diogo de Figueiredo. Apontamentos sobre o controle judicial das políticas públicas. In: FORTINI, Cristiana; ESTEVES, Júlio César dos Santos; DIAS, Maria Tereza Fonseca (Orgs.). Políticas públicas: possibilidades e limites. Belo Horizonte: Fórum, 2008. 377 p.

NIEBUHR, Joel de Menezes. O novo regime constitucional da medida provisória. São Paulo: Dialética, 2001.

OLIVEIRA, Régis Fernandes de; HORVATH, Estevão. Manual de Direito Financeiro. São Paulo: Revista dos Tribunais, 2003. 
PINTO, Élida Graziane. Contingenciamento de despesas e esvaziamento do controle legislativo sobre a execução orçamentária. In: FORTINI, Cristiana; ESTEVES, Júlio César dos Santos; DIAS, Maria Tereza Fonseca (Orgs.). Políticas públicas: possibilidades e limites. Belo Horizonte: Fórum, 2008. 377 p. PONTES FILHO, Valmir. O controle das políticas públicas. In: FORTINI, Cristiana; ESTEVES, Júlio César dos Santos; DIAS, Maria Tereza Fonseca (Orgs.). Políticas públicas: possibilidades e limites. Belo Horizonte: Fórum, 2008. $377 \mathrm{p}$.

ROSA, Alexandre Morais da. Garantismo jurídico e controle de constitucionalidade material. Florianópolis: Habitus, 2002.

SARLET, Ingo Wolfgang. A eficácia dos direitos fundamentais: uma teoria geral dos direitos fundamentais na perspectiva constitucional. 11. ed. Porto Alegre: Livraria do Advogado, 2009.

STRECK, Lenio Luiz. Hermenêutica jurídica e (m) crise: uma exploração hermenêutica da construção do direito. 8. ed. Porto Alegre: Livraria do Advogado, 2009.

TORRES, Ricardo Lobo. Curso de direito financeiro e tributário. 17. ed. Rio de Janeiro: Renovar, 2010.

Tratado de direito constitucional financeiro e tributário. 2. ed. Rio de Janeiro: Renovar, 2002.

VILLALÓN, Pedro Cruz. La curiosidad del jurista Persa, y otros estudios sobre la Constituición. Madrid: Centro de estudios políticos y constitucionales, 1999.

Recebido em: 4/4/2013

Revisado em: 4/6/2013

Aceito em: 13/6/2013 